\title{
Estabilidade aeróbia de silagens do capim-marandu submetidas a diferentes intensidades de compactação na ensilagem ${ }^{1}$
}

\section{Rafael Camargo do Amaral ${ }^{2}$, Thiago Fernandes Bernardes ${ }^{3}$, Gustavo Rezende Siqueira ${ }^{4}$, Ricardo Andrade Reis ${ }^{5}$}

\author{
1 Projeto financiado pela FAPESP. \\ 2 Programa de Pós-graduação em Ciência Animal e Pastagens - ESALQ/USP. Bolsista FAPESP. \\ ${ }^{3}$ Pós-doutorando ESALQ/USP. Bolsista FAPESP. \\ 4 APTA Colina e Doutorando em Zootecnia - FCAV/UNESP \\ ${ }^{5}$ Departamento de Zootecnia - FCAVIUNESP. Pesquisador do CNPq.
}

RESUMO - Objetivou-se avaliar a estabilidade aeróbia das silagens de capim-marandu submetidas a diferentes pressões de compactação. A espécie forrageira foi colhida aos 60 dias de crescimento vegetativo. O delineamento experimental utilizado foi o inteiramente casualizado com quatro repetições, utilizando-se o modelo de medidas repetidas no tempo. Os tratamentos constituíram-se de quatro densidades $\left(100,120,140\right.$ e $\left.160 \mathrm{~kg} \mathrm{MS} / \mathrm{m}^{3}\right)$. As alterações químicas das silagens foram determinadas com 0, 3 e 6 dias após a abertura. As leituras das temperaturas das silagens foram obtidas em intervalos de 12 horas, 156 horas após a acomodação dos baldes na câmara climática, utilizando-se o termômetro inserido a $10 \mathrm{~cm}$ no centro da massa de silagem. As silagens de maiores valores de densidade alcançaram máxima temperatura em maior tempo que as densidades inferiores, evidenciando a maior estabilidade decorrente de melhor compactação da massa ensilada. Com o avançar do tempo de exposição aeróbia, as silagens tiveram aumento nos valores de $\mathrm{pH}$ e decréscimos nos teores de nitrogênio amoniacal $\left(\mathrm{N}_{-} \mathrm{NH}_{3}\right)$. Verificou-se queda nos teores de NIDN (nitrogênio insolúvel em detergente neutro) e da fração B3 com o aumento da densidade, o que caracterizou a participação dessa fração durante o processo de proteólise após a quebra da vedação. Os teores de fibras em detergente neutro e detergente ácido durante a exposição ao ar sofreram acréscimo, sendo os maiores valores obtidos nas silagens de menor densidade. As silagens mais densas apresentaram maiores coeficientes de digestibilidade verdadeira in vitro que os demais tratamentos.

Palavras-chave: aerobiose, Brachiaria brizantha, compactação, perdas, silagem

\section{Aerobic stability of marandu grass silages submitted to different packing intensities during ensiling}

\begin{abstract}
This trial aimed to evaluate the aerobic stability of marandu grass silages submitted to different packing intensities. The forage was harvested at 60 days of regrowth. The following packing densities were evaluated: 100, 120, 140, and $160 \mathrm{~kg} \mathrm{DM} / \mathrm{m}^{3}$. Silage chemical changes were determined 0,3 , and 6 days after air exposure and temperature recorded every 12 hours, during 156 hours after the buckets were placed in the climatic camera. Thermometers were inserted $10 \mathrm{~cm}$ into the silage mass. Data were analyzed following a repeated measures model in a complete randomized design with four replications. The silage with the highest density reached the maximum temperature value in a longer period, compared to the lowest density one, probably due to the highest stability. The $\mathrm{pH}$ values increased and ammoniacal nitrogen $\left(\mathrm{N}-\mathrm{NH}_{3} / \mathrm{TN}\right)$ decreased during the air exposure phase. The NDIN (neutral detergent insoluble nitrogen) and B3 fractions decreased for the highest density silage, characterizing the participation of these fractions in the proteolysis process during the aerobic phase. The NDF (neutral detergent fiber) and ADF (acid detergent fiber) values increased during the aerobic exposure and the highest values were observed on the lowest density silages. The highest density silages showed higher true in vitro digestibility values compared to the other silages.
\end{abstract}

Key Words: aerobic phase, Brachiaria brizantha, losses, packing densities, silage

\section{Introdução}

Na abertura do silo, o ambiente anaeróbio, um dos responsáveis pela conservação da forragem, passa a ser aeróbio. Nessa ocasião, organismos que estavam em dormência na ausência de oxigênio multiplicam-se rapidamente, promovendo intensa atividade metabólica, gerando calor e consumindo nutrientes. A presença de oxigênio na 
silagem determina a multiplicação de alguns grupos de microrganismos aeróbios que consomem os compostos energéticos presentes, elevando as perdas de matéria seca (MS) e reduzindo o valor nutritivo do alimento (Pahlow et al., 2003).

O acúmulo de temperatura após a abertura do silo é reflexo da intensidade de reações promovidas por fungos filamentosos, leveduras e bactérias aeróbias. Bernardes et al. (2007) caracterizaram estabilidade aeróbia de silagens de capim-marandu por meio da elevação de temperatura e de alterações no valor nutritivo. Por outro lado, Jobim et al. (1999), trabalhando com silagens de grãos úmidos de milho e espigas de milho, e Guim et al. (2002), com silagens de capim-elefante emurchecido, utilizaram a contagem total de leveduras, fungos filamentosos e enterobactérias para caracterizar o processo de deterioração aeróbia das silagens.

Bernardes et al. (2005) observaram que a deterioração aeróbia em silagens de capins tropicais é caracterizada principalmente por bactérias aeróbias, em vez de fungos e leveduras, por estas apresentarem alto teor de umidade, reduzida acidez e baixa fonte de nutrientes disponíveis na massa ensilada. Além disso, silagens com estas características apresentam fermentações secundárias, o que impede a intensa atividade de microrganismos deterioradores (Bernardes et al., 2007).

Segundo Ruppel et al. (1995), a densidade da massa de forragem observada no fechamento do silo determina a qualidade final da silagem. A densidade e o teor de MS da forragem indicam a porosidade da silagem, que influencia a taxa de movimentação do ar e, sucessivamente, o potencial de deterioração durante o armazenamento e após a abertura do silo (Holmes \& Muck, 1999). Dessa forma, silagens que apresentam compactações mais elevadas (200 kg MS/m³), geralmente, contêm maiores teores de ácido lático e açúcares remanescentes provenientes da fermentação, o que prejudicaria a estabilidade aeróbia após a abertura do silo.

Objetivou-se com este trabalho avaliar a estabilidade aeróbia e as alterações na composição química após a abertura dos silos em silagens de capim-marandu submetidas a diferentes intensidades de compactação na ensilagem.

\section{Material e Métodos}

Este experimento foi conduzido nas dependências da Faculdade de Ciências Agrárias e Veterinárias/UNESP, no município paulista de Jaboticabal.

Para a uniformização da área utilizada, foi realizado um corte de rebaixamento, retirando-se toda a forragem do local, e em seguida foi efetuada uma aplicação de $150 \mathrm{~kg} / \mathrm{ha}$ de uréia no mês de fevereiro de 2004. A Brachiaria brizantha cv. Marandu foi colhida no dia 23 de abril de 2004, quando apresentava 60 dias de crescimento vegetativo (32\% MS), utilizando-se colhedora marca Casale ${ }^{\circledR}$ modelo CFC 180 AP, regulada para que o corte fosse realizado a $15 \mathrm{~cm}$ do solo.

O tamanho de partículas foi estimado por meio da ponderação da proporção de retenção do capim em peneiras, sendo definida a proporção do material retido com abertura superior a 31,7 mm, material retido com abertura entre 31,7 e 15,9 mm, 15,9 e 12,7 mm, 12,7 e 9,52 mm, 9,52 e 7,93 mm e 7,93 e 6,35 mm, respectivamente.

O delineamento experimental utilizado foi o inteiramente casualizado com quatro tratamentos e quatro repetições, utilizando-se o modelo de medidas repetidas no tempo, constituído pelos seguintes tratamentos: Brachiaria brizantha ensilada com densidade média de 100, 120, 140 e $160 \mathrm{~kg} \mathrm{MS} / \mathrm{m}^{3}$, definidos por meio da quantidade de forragem a ser ensilada em função do volume fixo do balde.

Para confecção dos 16 silos experimentais, foram utilizados baldes plásticos com capacidade para 7 litros, com tampas apropriadas para garantir a vedação adequada. $\mathrm{Na}$ parte inferior foram adicionados cerca de $3 \mathrm{~kg}$ (2 litros) de areia fina e seca e, logo acima, colocada uma tela protetora para evitar o contato da areia com a forragem e permitir o escoamento do efluente produzido. Na extremidade superior de cada silo experimental, foi instalada uma válvula do tipo "Bunsen” para escape dos gases produzidos.

A forragem foi compactada por meio de bastões de ferro, com acomodação de camadas de aproximadamente $10 \mathrm{~cm}$ de espessura. Com a acomodação final da forragem, os silos foram fechados e vedados com fitas plásticas adesivas na tentativa de evitar a entrada de ar nos baldes, que foram armazenados em local protegido e mantidos sob temperatura ambiente.

Foi necessária a determinação do teor de MS no momento da ensilagem para o cálculo das densidades propostas em $\mathrm{kg}$ de MS, sendo utilizada a metodologia de secagem em microondas, proposta por Souza (2003).

Decorridos 56 dias do fechamento, os silos foram abertos e em cada tratamento foi avaliada a composição química das silagens nos seguintes tempos: 0 (D0), 3 (D3) e 6 (D6) dias de exposição aeróbia, de modo que o tempo zero foi considerado o momento da abertura dos silos.

Imediatamente após a abertura dos silos, todo o conteúdo de silagem foi retirado e homogeneizado. Retirou-se aproximadamente $1 \mathrm{~kg}$ de silagem dos silos, sendo colocados em baldes plásticos com capacidade de $7 \mathrm{~L}$, que foram armazenados em câmara climática a $25 \pm 1^{\circ} \mathrm{C}$, para avaliação 
da estabilidade aeróbia. As temperaturas das silagens foram obtidas em intervalos de 12 horas durante 156 horas, perfazendo-se 14 tempos após a acomodação dos baldes na câmara climática, com o uso de termômetro inserido a $10 \mathrm{~cm}$ no centro da massa de silagem. A temperatura do ambiente foi controlada pelo termostato do aparelho refrigerador e também por meio de termômetros suspensos no ar. A estabilidade aeróbia foi calculada como o tempo observado para que a silagem, após a abertura do silo, apresentasse elevação em $1^{\circ} \mathrm{C}$ em relação à temperatura ambiente (Driehuis et al., 2001).

A determinação da taxa de recuperação da MS foi obtida pelo quociente entre a quantidade de MS recuperada dos baldes ( $3 \underline{0}$ e $6 \underline{0}$ dias) e a quantidade de MS inicialmente acondicionada nos baldes (abertura) e expressa em porcentagem.

Após a abertura dos silos, as amostras foram coletadas na abertura (D0), no 3ํㅡ e $6 \stackrel{0}{0}$ dias e divididas em duas frações. A primeira foi utilizada para determinação dos teores de MS e proteína bruta (PB), conforme a AOAC (1980), concentrações de fibra em detergente neutro (FDN) e fibra em detergente ácido (FDA) pelo método seqüencial, segundo as técnicas descritas por Robertson \& Van Soest (1981). Para determinação da celulose, foi utilizado o ácido sulfúrico a $72 \%$ (Van Soest, 1994). Os teores de hemicelulose foram calculados por diferença entre FDN e FDA, e a lignina, por diferença entre FDA e celulose. Nova análise de FDN e FDA foi realizada para, a partir desses resíduos, serem procedidas as análises de nitrogênio insolúvel em detergente neutro (NIDN) e nitrogênio insolúvel em detergente ácido (NIDA). A determinação da fração B3 foi calculada pela diferença entre o NIDN e NIDA. A digestibilidade verdadeira in vitro da MS (DVIVMS) foi estimada com base nos procedimentos descritos por Silva \& Queiroz (2002). A segunda porção foi processada em liquidificador, segundo metodologia descrita por Kung Jr. et al. (1984), para obtenção do extrato aquoso, o qual foi utilizado para determinar os teores de nitrogênio amoniacal $\left(\mathrm{N}-\mathrm{NH}_{3}\right)$, segundo AOAC (1980), e pH, com o uso do potenciômetro (Silva \& Queiroz, 2002).

Os dados foram analisados utilizando o Programa de Análise Estatística SAS ${ }^{\circledR}$ (1985), pelo procedimento MIXED, sendo que para comparação entre médias empregou-se o teste Tukey, adotando-se 5\% como nível de significância. Quando necessária, a exploração das tendências foi acompanhada da declaração do nível de significância observado.

\section{Resultados e Discussão}

As densidades obtidas neste trabalho foram de 97,4; 118,6; 139,2 e 164,0 kg MS/m³ , para as pressões decompactação de $100,120,140$ e $160 \mathrm{~kg} \mathrm{MS} / \mathrm{m}^{3}$, respectivamente.

Não houve quebra da estabilidade aeróbia das silagens, de acordo com a metodologia imposta ao estudo (elevação da temperatura da silagem acima de $26^{\circ} \mathrm{C}$ ), porém as silagens com maiores densidades (120, 140 e $160 \mathrm{~kg} \mathrm{MS} / \mathrm{m}^{3}$ ) apresentaram maior elevação de temperatura em relação à densidade de $100 \mathrm{~kg} \mathrm{MS} / \mathrm{m}^{3}$ após 12 horas de exposição ao ar (Figura 1). Possivelmente, o melhor padrão de fermentação das silagens com densidades superiores proporcionou maior quantidade de substratos disponíveis para consumo dos microrganismos na fase aeróbia. Este resultado confirma inferências de Amaral et al. (2007), que, trabalhando com silagens de capim-marandu

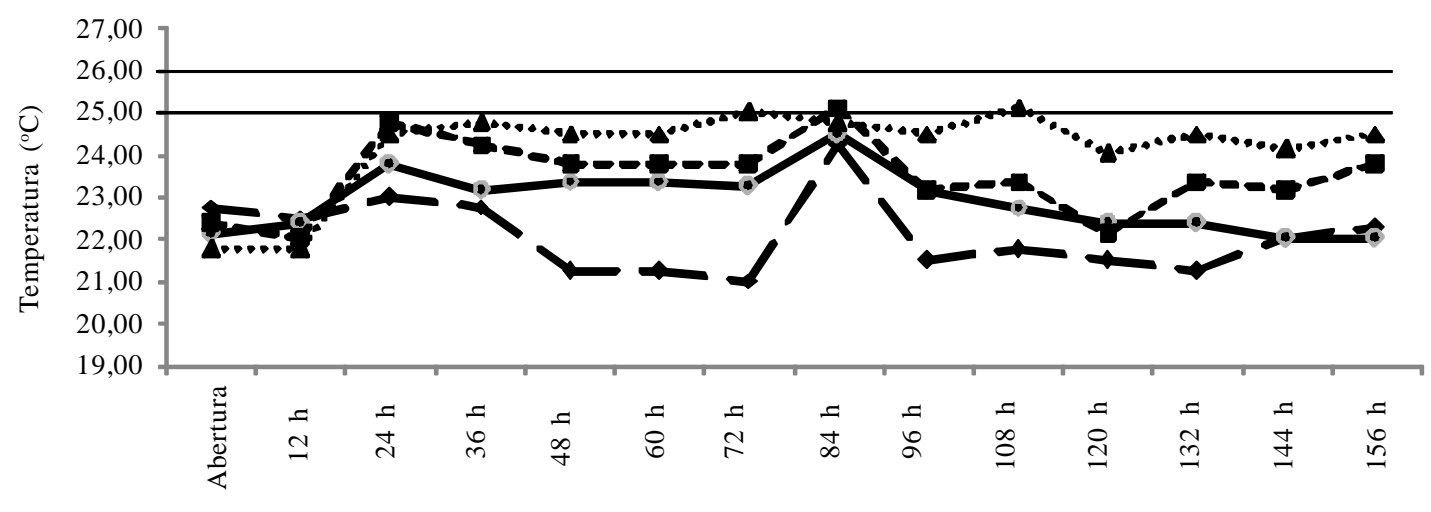

Horas de exposição das silagens ao ar

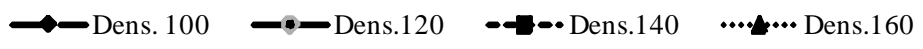

Figura 1 - Temperatura das silagens de capim-marandu submetidas a diferentes densidades na ensilagem ao longo do período de exposição aeróbia. 
com diferentes pressões de compactação, verificaram que as silagens melhores compactadas apresentaram melhor padrão fermentativo ( $\mathrm{pH}$ reduzido, menores concentrações de amônia e maior recuperação de MS), resultando em menores perdas durante a ensilagem.

Silagens de capins tropicais expostas ao ar possuem prevalência de bactérias aeróbias, em virtude de sua estabilidade de fermentação ocorrer em $\mathrm{pH}$ acima de 4,5, de seu alto teor de umidade e da ausência de substratos (Bernardes et al., 2003). Este resultado corrobora os obtidos por Bernardes et al. (2005), que verificaram que silagens de capim-marandu adicionadas de polpa cítrica peletizada apresentaram estabilidade das temperaturas no pós-abertura, por essas serem caracterizadas pela predominância de bactérias aeróbias (enterobactérias), em vez de fungos e leveduras. Possivelmente, as silagens utilizadas neste trabalho foram também caracterizadas pela presença de bactérias aeróbias, as quais não produzem calor com tanta eficiência como fungos filamentosos e leveduras (Pahlow et al., 2003), fato que gerou a estabilidade das temperaturas das silagens.

As silagens com densidades 100, 120 e $140 \mathrm{~kg} \mathrm{MS} / \mathrm{m}^{3}$ alcançaram máxima temperatura entre 81 e 84 horas de exposição ao ar, ao passo que somente após 95 horas este fato foi observado para o tratamento com densidade de $160 \mathrm{~kg} \mathrm{MS} / \mathrm{m}^{3}$ (Figura 2). Apesar de as silagens não apresentarem elevação da temperatura acima da temperatura ambiente (Figura 1), esta sofreu deterioração, fato evidenciado pelos dados de pH e recuperação de MS encontrados. O tratamento com maior densidade $\left(160 \mathrm{~kg} \mathrm{MS} / \mathrm{m}^{3}\right)$ apresentou maior tempo para alcançar a máxima temperatura, porém atingiu maiores valores de temperatura, o que possivelmente

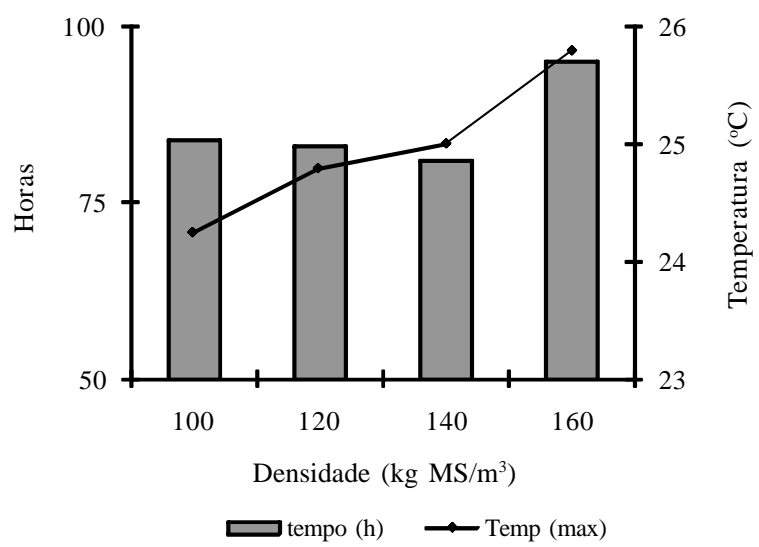

Figura 2 - Tempo para máxima temperatura e temperatura máxima de silagens de capim-marandu submetidas a diferentes densidades na fermentação durante o período de exposição aeróbia. pode estar relacionado a um melhor padrão fermentativo dessas silagens, o qual gerou maior concentração de substratos e, conseqüentemente, maior atividade microbiológica.

Houve efeito dos dias em aerobiose $(\mathrm{P}<0,05)$, sendo que não foi verificada diferença $(\mathrm{P}>0,05)$ entre as densidades. $\mathrm{O}$ possível motivo dessa elevação nos teores de MS no decorrer do período de aerobiose justifica-se pelo fato de que, na região onde o trabalho foi desenvolvido, são encontrados baixos (65-70\%) valores de umidade relativa do ar.

Houve efeito significativo dos dias de exposição ao ar e das densidades $(\mathrm{P}<0,05)$ para os valores de $\mathrm{pH}$, não sendo verificada interação dia $\times$ densidade (Tabela 1 ).

Com o avanço no tempo de exposição, as silagens tiveram seus valores de $\mathrm{pH}$ elevados, sendo que, nos tratamentos de maior densidade (140 e $160 \mathrm{~kg} \mathrm{MS} / \mathrm{m}^{3}$ ), verificou-se menor elevação em relação aos demais tratamentos. Possivelmente, o acréscimo nos valores de $\mathrm{pH}$ deve-se à degradação do ácido lático por parte dos microrganismos aeróbios, para obtenção de energia (Woolford, 1990), e à perda de outros ácidos orgânicos por volatilização. Os altos teores de $\mathrm{pH}$ obtidos nesta pesquisa provavelmente devem-se às condições impostas às silagens com 100 e $120 \mathrm{~kg} \mathrm{MS} / \mathrm{m}^{3}$ de densidade, tendo levado à fermentação inadequada, o que se traduziu em acúmulo de prejuízos.

Houve efeito dos dias de aeração e das densidades $(\mathrm{P}<0,05)$ sobre os valores de nitrogênio amoniacal (Tabela 1 ). À medida que os tempos de exposição aeróbia avançaram, as silagens apresentaram redução nos teores médios de nitrogênio amoniacal, provavelmente devido ao processo evaporativo. Entre as densidades, observaram-se maiores valores nas de maior grau de compactação. Provavelmente, as silagens com densidades de 140 e $160 \mathrm{~kg} \mathrm{MS} / \mathrm{m}^{3}$ sofreram mais intensamente a ação de bactérias proteolíticas, as quais degradam proteína e transformam-nas em amônia, condizendo com os dados apresentados na Tabela 2 referentes aos valores de proteína bruta das silagens.

Pitt et al. (1991) desenvolveram um modelo na intenção de avaliar a estabilidade aeróbia de silagens, usando como parâmetros a temperatura, o pH, a concentração de carboidratos solúveis e outros, porém não incluíram a produção de amônia. Todavia, destacaram que, para determinadas culturas, esse parâmetro é um importante indicador de instabilidade em silagens.

Não foi verificada diferença (Tabela 2) nos teores de PB ao longo do período de exposição aeróbia $(\mathrm{P}>0,05)$, porém houve diferença entre as densidades $(\mathrm{P}<0,05)$. Os tratamentos com densidades de 140 e $160 \mathrm{~kg}$ MS/m³ apresentaram valores inferiores aos tratamentos com 100 e $120 \mathrm{~kg} \mathrm{MS} / \mathrm{m}^{3}$, possivelmente as silagens mais densas sofreram proteólise com o prolongamento do tempo de exposição ao ar, eviden- 
Tabela 1 - Teores de matéria seca (MS), pH e nitrogênio amoniacal $\left(\mathrm{N}_{-} \mathrm{NH}_{3}\right)$ das silagens de capim-marandu submetidas a diferentes densidades ao longo dos tempos de exposição aeróbia

\begin{tabular}{|c|c|c|c|c|c|c|c|c|c|c|c|}
\hline \multirow[t]{2}{*}{ Item } & \multicolumn{3}{|c|}{ Dia $(A)$} & \multicolumn{4}{|c|}{ Densidade (kg MS/m³) (B) } & \multicolumn{4}{|c|}{ Efeito } \\
\hline & 0 & 3 & 6 & 100 & 120 & 140 & 160 & A & B & $A \times B$ & $\mathrm{EPM}^{1}$ \\
\hline MS, \% & $31,9 c$ & $41,4 b$ & $66,0 \mathrm{a}$ & 47,1 & 47,3 & 47,4 & 43,9 & $* *$ & 0,4 & 0,2 & 3,0 \\
\hline $\mathrm{pH}$ & $5,8 c$ & $6,9 b$ & $7,8 \mathrm{a}$ & $7,7 \mathrm{a}$ & $8,2 \mathrm{a}$ & $5,7 b$ & $5,7 b$ & $* *$ & $* *$ & 0,7 & 0,4 \\
\hline $\mathrm{N}-\mathrm{NH}_{3}, \%$ Ntotal & $10,2 \mathrm{a}$ & $6,9 b$ & $7,8 b$ & $6,8 b$ & $6,8 b$ & $10,4 a$ & $9,2 \mathrm{ab}$ & $* *$ & $* *$ & 0,3 & 1,3 \\
\hline
\end{tabular}

Médias seguidas da mesma letra não diferem entre si $(P>0,05)$; 0: dia 0 (abertura), 3: 3으 dia em aerobiose, 6: 6으 dia em aerobiose.

${ }^{1}$ EPM: erro-padrão da média; * $\mathrm{P}<0,05 ;{ }^{* *} \mathrm{P}<0,01$.

Tabela 2 - Teores de proteína bruta (PB) e nitrogênio insolúvel em detergente ácido (NIDA) das silagens de capim-marandu submetidas a diferentes densidades ao longo dos tempos de exposição aeróbia

\begin{tabular}{|c|c|c|c|c|c|c|c|c|c|c|c|}
\hline \multirow[t]{2}{*}{ Item } & \multicolumn{3}{|c|}{ Dia (A) } & \multicolumn{4}{|c|}{ Densidade (kg MS/m³) (B) } & \multicolumn{4}{|c|}{ Efeito } \\
\hline & 0 & 3 & 6 & 100 & 120 & 140 & 160 & A & B & $A \times B$ & $\mathrm{EPM}^{1}$ \\
\hline $\mathrm{PB}, \% \mathrm{MS}$ & 4,8 & 5,0 & 4,9 & $5,3 a$ & $5,2 \mathrm{ab}$ & $4,5 c$ & $4,7 \mathrm{bc}$ & 0,4 & $* *$ & 0,9 & 0,2 \\
\hline NIDA, \% Ntotal & 18,1 & 17,9 & 19,4 & $18,7 a b$ & $21,8 \mathrm{a}$ & $17,1 \mathrm{~b}$ & $16,2 b$ & 0,4 & $* *$ & 0,7 & 1,6 \\
\hline
\end{tabular}

Médias seguidas da mesma letra não diferem entre si $(P>0,05)$; 0: dia 0 (abertura), 3: 3으 dia em aerobiose, 6: 6으 dia em aerobiose.

${ }^{1}$ EPM: erro-padrão da média; ${ }^{*} \mathrm{P}<0,05 ;{ }^{* *} \mathrm{P}<0,01$.

ciado pela elevação dos teores de nitrogênio amoniacal (Tabela 1) e, conseqüentemente, pela redução nos teores de proteína bruta. Segundo Bernardes et al. (2005), em silagens de capins tropicais, essa proteólise é verificada pelo desenvolvimento de enterobactérias e bacilos que apresentam amplo crescimento após a quebra da vedação. Outro fator que também comprova a baixa estabilidade dessas silagens são os valores de $\mathrm{pH}$, que sofreram pronunciado aumento durante a exposição aeróbia.

Os teores de nitrogênio insolúvel em detergente ácido (Tabela 2) não apresentaram diferença entre os dias de aeração ( $\mathrm{P}>0,05)$, porém, as densidades de maior valor (140 e $160 \mathrm{~kg} \mathrm{MS} / \mathrm{m}^{3}$ ) apresentaram valores diminutos em relação aos tratamentos com 100 e $120 \mathrm{~kg} \mathrm{MS} / \mathrm{m}^{3}$ $(\mathrm{P}<0,05)$. Segundo Van Soest (1994), a condensação de carboidratos com qualquer grupo amina livre em temperatura acima de $55^{\circ} \mathrm{C}$ forma polímeros que elevam os teores de nitrogênio ligado à fibra. $\mathrm{O}$ aquecimento das silagens pela ação dos microrganismos pode promover essas reações, influenciando os resultados de NIDA. Porém, essa hipótese não é válida para este estudo, pois, após a quebra da vedação, foram registradas baixas temperaturas ambientais (Figura 2).

Os teores de NIDN do tratamento com $100 \mathrm{~kg} \mathrm{MS} / \mathrm{m}^{3}$ de densidade sofreram decréscimo (Tabela 3 ) durante o período de exposição ao ar $(\mathrm{P}<0,05)$, não havendo diferença nas outras densidades $(\mathrm{P}>0,05)$. Entre as densidades verificou-se queda nos teores com o aumento da densidade, o que caracterizou a participação da fração B3 (Tabela 4) durante o processo de proteólise após a quebra da vedação, onde pode ser observado aumento nos teores de nitrogênio amoniacal.

Houve diferença nos valores médios da fração B3 (Tabela 4) durante a exposição ao ar e entre as densidades $(\mathrm{P}<0,05)$. Observou-se declínio desta fração com o prolongamento dos dias de exposição ao ar e com o aumento no valor das densidades. Possivelmente, houve proteólise por parte da ação de microrganismos, os quais utilizam esta fração para obtenção de energia, concordando com Bernardes et al. (2005), que, estudando silagem de capimmarandu, também verificaram queda nos teores da fração B3.

Os teores de FDN e FDA durante o período de exposição ao ar sofreram acréscimo $(\mathrm{P}<0,05)$, sendo os maiores valores obtidos nas silagens com 100 e $120 \mathrm{~kg} \mathrm{MS} / \mathrm{m}^{3}$ (Tabela 5). Essa maior concentração nos teores de FDN e FDA, possivelmente, se deve ao maior consumo de constituintes do conteúdo celular da planta por parte dos microrganismos, tanto na fase fermentativa como no pós-abertura.

Em relação aos teores de hemicelulose, não foi verificada diferença entre os dias de aeração, porém houve diferença $(\mathrm{P}<0,05)$ entre as densidades, de modo que as silagens com 100 e $120 \mathrm{~kg} \mathrm{MS} / \mathrm{m}^{3}$ apresentaram menores valores que as com 140 e $160 \mathrm{~kg} \mathrm{MS} / \mathrm{m}^{3}$ de densidade. Provavelmente, a degradação deste carboidrato deveu-se à atuação de fungos filamentosos e leveduras, o que foi traduzido em decréscimo nos teores de hemicelulose.

Com o decorrer da exposição das silagens ao ar, verificou-se elevação nos valores de lignina $(\mathrm{P}<0,05)$, não se 
Tabela 3 - Teores de nitrogênio insolúvel em detergente neutro (\%NIDN/ $\mathrm{N}$ total) das silagens de capim-marandu submetidas a diferentes densidades ao longo dos tempos de exposição aeróbia

\begin{tabular}{lllll}
\hline Densidade $^{1}$ & \multicolumn{3}{c}{ Dias em aerobiose } & \multirow{2}{*}{ Média } \\
\cline { 2 - 4 } & \multicolumn{1}{c}{0} & \multicolumn{1}{c}{3} & \multicolumn{1}{c}{6} \\
\hline 100 & $34,3 \mathrm{aA}$ & $27,8 \mathrm{bA}$ & $27,8 \mathrm{bA}$ & $30,0 \mathrm{~A}$ \\
120 & $29,5 \mathrm{aB}$ & $28,6 \mathrm{aA}$ & $26,5 \mathrm{aAB}$ & $28,2 \mathrm{~A}$ \\
140 & $22,9 \mathrm{aC}$ & $20,3 \mathrm{aB}$ & $23,7 \mathrm{aAB}$ & $22,3 \mathrm{~B}$ \\
160 & $20,4 \mathrm{aC}$ & $24,3 \mathrm{aAB}$ & $23,1 \mathrm{aB}$ & $22,6 \mathrm{~B}$ \\
Média & $26,8 \mathrm{a}$ & $25,2 \mathrm{a}$ & $25,3 \mathrm{a}$ & 25,8 \\
EPM $^{2}$ & & & & 1,6 \\
\hline
\end{tabular}

Médias seguidas da mesma letra, minúsculas na linha e maiúsculas na coluna não diferem $(P>0,05)$ entre si.

${ }^{1}$ Densidades em kg MS/m³; ${ }^{2}$ EPM: erro-padrão da média.
Tabela 4 - Teores da fração B3 (\% N total) das silagens de capim-marandu submetido a diferentes densidades ao longo dos tempos de exposição aeróbia

\begin{tabular}{lcccc}
\hline Densidade $^{1}$ & \multicolumn{3}{c}{ Dias em aerobiose } & \multirow{2}{*}{ Média } \\
\cline { 2 - 4 } & 0 & 3 & 6 & \\
\hline 100 & $16,0 \mathrm{aA}$ & $8,7 \mathrm{bAB}$ & $9,0 \mathrm{bA}$ & $11,2 \mathrm{~A}$ \\
120 & $8,0 \mathrm{aB}$ & $6,2 \mathrm{aAB}$ & $4,8 \mathrm{aAB}$ & $6,3 \mathrm{~B}$ \\
140 & $5,4 \mathrm{aB}$ & $4,6 \mathrm{aB}$ & $5,5 \mathrm{aAB}$ & $5,2 \mathrm{~B}$ \\
160 & $5,3 \mathrm{bB}$ & $9,8 \mathrm{aA}$ & $4,2 \mathrm{bB}$ & $6,4 \mathrm{~B}$ \\
Média $^{2}$ & $8,7 \mathrm{a}$ & $7,3 \mathrm{ab}$ & $5,9 \mathrm{~b}$ & 7,3 \\
EPM $^{2}$ & & & & 1,5 \\
\hline
\end{tabular}

Médias seguidas da mesma letra, minúsculas na linha e maiúsculas na coluna não diferem $(P>0,05)$ entre si.

${ }^{1}$ Densidades em kg MS/m³; ${ }^{2}$ EPM: erro-padrão da média.

Tabela 5 - Valores de fibra em detergente neutro (FDN), fibra em detergente ácido (FDA), hemicelulose (HEM), lignina (LIG) e digestibilidade verdadeira in vitro da matéria seca (DVIVMS) das silagens de capim-marandu submetido a diferentes densidades ao longo dos tempos de exposição aeróbia

\begin{tabular}{|c|c|c|c|c|c|c|c|c|c|c|c|}
\hline \multirow[t]{2}{*}{ Item } & \multicolumn{3}{|c|}{ Dia (A) } & \multicolumn{4}{|c|}{ Densidade $\left(\mathrm{kg} \mathrm{MS} / \mathrm{m}^{3}\right)$ (B) } & \multicolumn{4}{|c|}{ Efeito } \\
\hline & 0 & 3 & 6 & 100 & 120 & 140 & 160 & A & B & $\mathrm{A} \times \mathrm{B}$ & $\mathrm{EPM}^{1}$ \\
\hline FDN, \% MS & $78,1 b$ & $80,0 \mathrm{a}$ & $79,3 a$ & $79,0 \mathrm{~b}$ & $80,9 a$ & $79,0 \mathrm{~b}$ & $77,6 b$ & $* *$ & $* *$ & 0,1 & 0,6 \\
\hline HEM, \% MS & 37,8 & 38,2 & 37,9 & $37,8 a b$ & $37,1 b$ & $38,6 a$ & $38,4 a$ & 0,4 & $* *$ & 0,4 & 0,5 \\
\hline LIG, \% MS & $6,3 b$ & $7,4 a$ & $7,5 a$ & 7,3 & 7,3 & 7,3 & 6,5 & $* *$ & 0,3 & 0,7 & 0,5 \\
\hline DVIVMS, \% & 57,4 & 60,1 & 58,3 & $58,8 \mathrm{a}$ & $54,4 \mathrm{~b}$ & $59,3 a$ & $61,8 \mathrm{a}$ & 0,1 & $* *$ & 0,3 & 1,6 \\
\hline
\end{tabular}

Médias seguidas da mesma letra não diferem entre si ( $P>0,05)$; 0: dia 0 (abertura), 3: 3o dia em aerobiose, 6: 60 dia em aerobiose.

${ }^{1}$ EPM: erro-padrão da média; * $\mathrm{P}<0,05 ;{ }^{* *} \mathrm{P}<0,01$.

verificando diferença entre as densidades ( $\mathrm{P}>0,05)$, provavelmente em decorrência do acréscimo da fração fibrosa das silagens, pelo consumo de constituintes do conteúdo celular, que, dessa forma, concentrou os valores de lignina (Tabela 5).

A digestibilidade verdadeira in vitro da MS (Tabela 5) foi alterada entre os tratamentos $(P<0,05)$, não havendo diferença estatística durante a exposição aeróbia ( $\mathrm{P}>0,05)$. As silagens mais densas (140 e $160 \mathrm{~kg} \mathrm{MS} / \mathrm{m}^{3}$ ), juntamente com a silagem com densidade de $100 \mathrm{~kg} \mathrm{MS} / \mathrm{m}^{3}$, apresentaram coeficientes de digestibilidade superiores àquele com densidade de $120 \mathrm{~kg} \mathrm{MS} / \mathrm{m}^{3}$. Possivelmente, esses maiores valores para as silagens mais densas deveu-se à maior concentração de substratos para o desenvolvimento de microrganismos ruminais, pois, segundo Van Soest (1994), o lactato é degradado no rúmen produzindo 2 ATPs durante a fermentação ruminal, ou seja, gera a metade de energia quando comparado à glicose (4 ATPs), sustentando crescimento microbiano.

Durante a exposição ao ar, os teores médios de celulose (Tabela 6) não diferiram estatisticamente. Já entre as densidades verificou-se diminuição nos teores à medida que se elevaram as densidades $(\mathrm{P}<0,05)$. $\mathrm{O}$ aumento dos teores de
Tabela 6 - Teores de celulose (\% MS) das silagens de capimmarandu, submetido a diferentes densidades ao longo dos tempos de exposição aeróbia

\begin{tabular}{lllll}
\hline Densidade $^{1}$ & \multicolumn{3}{c}{ Dias em aerobiose } & \multirow{2}{*}{ Média } \\
\cline { 2 - 4 } & \multicolumn{1}{c}{0} & \multicolumn{1}{c}{3} & 6 & \\
\hline 100 & $33,9 \mathrm{aB}$ & $33,8 \mathrm{aB}$ & $34,3 \mathrm{aAB}$ & $34,0 \mathrm{~B}$ \\
120 & $36,5 \mathrm{abA}$ & $38,0 \mathrm{aA}$ & $35,2 \mathrm{bA}$ & $36,5 \mathrm{~A}$ \\
140 & $33,6 \mathrm{aB}$ & $32,5 \mathrm{aB}$ & $33,5 \mathrm{aAB}$ & $33,2 \mathrm{BC}$ \\
160 & $32,4 \mathrm{aB}$ & $32,9 \mathrm{aB}$ & $32,7 \mathrm{aB}$ & $32,7 \mathrm{C}$ \\
Média & $34,1 \mathrm{a}$ & $34,3 \mathrm{a}$ & $33,9 \mathrm{a}$ & 34,1 \\
EP M $^{2}$ & & & & 0,6 \\
\hline
\end{tabular}

Médias seguidas da mesma letra, minúsculas na linha e maiúsculas na coluna não diferem $(P>0,05)$ entre si.

${ }^{1}$ Densidades em $\mathrm{kg} \mathrm{MS} / \mathrm{m}^{3}$; ${ }^{2}$ EPM: erro-padrão da média.

celulose nas densidades menores (100 e $\left.120 \mathrm{~kg} \mathrm{MS} / \mathrm{m}^{3}\right)$ acompanhou a elevação nos teores da FDA.

Não houve diferença entre as densidades e entre os dias de aeração ( $\mathrm{P}>0,05)$. As silagens apresentaram recuperação média de MS de 92,9\% (Tabela 7), porém verificou-se no tratamento de menor densidade $\left(100 \mathrm{~kg} \mathrm{MS} / \mathrm{m}^{3}\right)$ tendência de menor recuperação. Resultados similares ao deste trabalho foram observados por Bernardes et al. (2007), trabalhando com silagens de capim-marandu, obtendo-se 
Tabela 7 - Taxa de recuperação da matéria seca das silagens de capim-marandu submetido a diferentes densidades ao longo dos tempos de exposição aeróbia

\begin{tabular}{lccc}
\hline Densidade $^{1}$ & \multicolumn{2}{c}{ Dias em aerobiose } & \multirow{2}{*}{ Média } \\
\cline { 2 - 3 } & 3 & 6 & \\
\hline 100 & 87,6 & 84,5 & $86,0 \mathrm{~A}$ \\
120 & 99,0 & 93,8 & $96,4 \mathrm{~A}$ \\
140 & 97,7 & 94,7 & $96,2 \mathrm{~A}$ \\
160 & 94,1 & 91,5 & $92,8 \mathrm{~A}$ \\
Média & $94,6 \mathrm{a}$ & $91,2 \mathrm{a}$ & 92,9 \\
EPM $^{2}$ & & & 3,9 \\
\hline
\end{tabular}

Médias seguidas da mesma letra, minúscula na linha e maiúscula na coluna não diferem $(P>0,05)$ entre si.

${ }^{1}$ Densidades em kg MS/m ${ }^{3} ;{ }^{2}$ EPM: erro-padrão da média.

recuperação de MS entre 93,6 e 94,5\% no 60 dia de exposição aeróbia.

\section{Conclusões}

As silagens de capim-marandu com maior grau de compactação têm sua estabilidade aeróbia mais prejudicada e maiores alterações em seu valor nutritivo em relação às silagens de menor densidade, em função do melhor padrão fermentativo, o que ocasiona maior oportunidade de deterioração por microrganismos aeróbios.

\section{Agradecimento}

À Fundação de Amparo à Pesquisa do Estado de São Paulo (FAPESP), pelo apoio financeiro ao projeto e pela concessão de bolsas de estudo.

\section{Literatura Citada}

AMARAL, R.C.; BERNARDES, T.F.; SIQUEIRA, G.R. et al. Características fermentativas e químicas de silagens de capimmarandu produzidas com quatro pressões de compactação. Revista Brasileira de Zootecnia, v.36, n.3, p.532-539, 2007. ASSOCIATION OF OFFICIAL AGRICULTURAL CHEMISTS AOAC. Official methods of analyses of the Association of Official analytical chemists. 13.ed. Washington: 1980. 1015p. BERNARDES, T.F.; REIS, R.A.; SCHOCKEN-ITURRINO, R.P. Dinâmica microbiológica e alterações químicas das silagens de capim-Marandu (Brachiaria brizantha cv. Marandu) após a abertura dos silos. In: REUNIÃO ANUAL DA SOCIEDADE BRASILEIRA DE ZOOTECNIA, 40., 2003, Santa Maria. Anais... Santa Maria: Sociedade Brasileira de Zootecnia, [2003]. (CD-ROM).
BERNARDES, T.F.; REIS, R.A.; MOREIRA, A.L. Fermentative and microbiological profile of Marandu-grass ensiled with citrus pulp pellets. Scientia Agricola, v.62, n.3, p.214-220, 2005.

BERNARDES, T.F.; REIS, R.A.; SIQUEIRA, G.R. et al. Estabilidade aeróbia da ração total e de silagens de capim-Marandu tratadas com aditivos químicos e bacterianos. Revista Brasileira de Zootecnia, v.36, n.4, p.754-762, 2007.

DRIEHUIS, F.; OUDE ELFERINK, W.H.; Van WIKSELAAR, P.G. Fermentation characteristics and aerobic stability of grass silage inoculant with Lactobacillus buchneri, with or without mofermentative lactic acid bacteria. Grass and Forage Science, v.56, p.330-343, 2001.

GUIM, A.; ANDRADE, P.; ITURRINO-SCHOCKEN, R.P. et al. Estabilidade aeróbia de silagens de capim-elefante (Pennisetum purpureum, Schum) emurchecido e tratado com inoculante microbiano. Revista Brasileira de Zootecnia, v.31, n.6, p.2176-2185, 2002.

HOLMES, B.J.; MUCK, R.E. Factors affecting bunker silos densities. Madison: University of Wisconsin, 1999. 7p.

JOBIM, C.C.; REIS, R.A.; SCHOKEN-ITURRINO R.P. et al. Desenvolvimento de microorganismos durante a utilização de silagens de grãos úmidos de milho sem brácteas. Acta Scientiarum, v.21, n.3, p.671-676, 1999.

KUNG JR., L.; GRIEVE, D.B.; THOMAS, J.W. Added ammonia or microbial inoculant for fermentation and nitrogenous compounds of alfafa ensiled at various percents of dry matter. Journal of Dairy Science, v.67, p.299-306, 1984.

KUNG JR., L. Aditivos microbianos e químicos para silagem - Efeitos na fermentação e resposta animal. In: WORKSHOP SOBRE MILHO PARA SILAGEM, 2., 2000, Piracicaba. Anais.. Piracicaba: Fundação de Estudos Agrários Luiz de Queiroz, 2001. p.53-74.

McDONALD, P.J.; HENDERSON, A.R.; HERON, S.J.E. The biochemistry of silage. 2.ed. Mallow: Chalcombe Publications, 1991. 340p.

PAHLOW, G.; MUCK, R.E.; DRIEHUIS, F. et al. Microbiology of ensiling. In: BUXTON, D.R.; MUCK, R.E.; HARRISON, J.H. (Eds.) Silage science and technology. 1.ed. Madison: American Society of Agronomy, 2003. p.31-94.

PITT, R.E.; MUCK, R.E.; PICKERING, N.B. A model of aerobic fungal growth in silage. 2. Aerobic stability. Grass and Forage Science, v.46, p.301-312, 1991.

ROBERTSON, J.B.; Van SOEST, P.J. The detergent system of analysis and its application to human foods. In: JAMES, W.P.T.; THEANDER, O. (Eds.) The analysis of dietary fiber in food. New York: Marcel Dekker, 1981. p.123-158.

RUPPEL, K.A.; PITT, R.E.; CHASE, L.E. et al. Bunker silo management and its relationship to forage preservation on dairy farms. Journal of Dairy Science, v.78, p.141-153, 1995.

STATISTICAL ANALYSIS SYSTEM - SAS. The SAS system for Windows: version 6.12 (compact disc). Cary: SAS Institute, 1985.

SILVA, D.J.; QUEIROZ, A.C. Análise de alimentos: métodos químicos e biológicos. 3.ed. Viçosa, MG: Editora UFV, 2002. $235 p$.

SOUZA, G.B. Pré-tratamento e caracterização dos constituintes nutricionais em amostras de alimento animal. São Carlos: Universidade de São Paulo, 2003. 75p. Dissertação (Mestrado em Ciências - Química Analítica) - Universidade de São Paulo, 2003.

Van SOEST, P.J. Nutritional ecology of the ruminant. 2.ed. Ithaca: Cornell University Press, 1994. 476p.

WOOLFORD, M.K. The detrimental effects of air on silage. Journal Applied Bacteriology, v.68, p.101-116, 1990. 